\title{
Radiographic Evaluation of Crestal Bone Levels of Delayed Single Implants with Two Different Neck Designs in the Posterior Maxilla: A Clinical Study
}

\section{Original Article}

\author{
Karim M. AbdelMohsen, Omar E. Mokhtar, Amr A. Ghanem and \\ Moustafa S. Taha
}

Department of Oral and Maxillofacial Surgery, Faculty of Dentistry, Ain Shams University, Cairo, Egypt

\begin{abstract}
Objectives: This study was conducted to compare the early radiographic bone level changes around delayed single implants in the posterior maxilla with different beveled smooth collar heights.

Materials and Methods: Thirteen patients with a missing posterior tooth in the maxilla were randomly allocated to be treated with an implant with either a beveled $1.5 \mathrm{~mm}$ smooth collar or a beveled $0.3 \mathrm{~mm}$ smooth collar. Implants were installed in healed sites and were loaded after 4 months. Follow-up visits were conducted 4 and 10 months after implant placement.

Results: Assessment of marginal bone levels showed Non-Significant $(P$-value $=0.05)$ differences in mesial and distal marginal bone level mean values between both groups within each follow-up period. Assessment of marginal bone loss showed NonSignificant $(P$-value $=0.05)$ differences in mesial and distal marginal bone loss mean values between both groups within each time interval.

Conclusion: For posterior tooth replacements, implants with different smooth collar heights showed similar and favorable radiographic outcomes with acceptable marginal bone loss after 6 months of loading.
\end{abstract}

Key Words: Crestal Bone Loss, Machined Collar, Marginal Bone Loss, Posterior Maxilla, Smooth Collar.

Received: 25 November 2019, Accepted: 10 April 2020.

Corresponding Author: Karim M. AbdelMohsen, Department of Oral and Maxillofacial Surgery, Faculty of Dentistry, Ain Shams University, Cairo, Egypt, Tel.: +201001479275, E-mail: karim.mohsen@dent.asu.edu.eg.

ISSN: 2090-097X, July 2019, Vol. 10, No. 3

\section{INTRODUCTION}

With the advent of implants and their introduction into field of surgical and restorative dentistry, there has been increasing research surrounding improving the success and survival rates of these implants. Albrektsson, Smith and Zarb have proposed criteria for successful implants describing an acceptable figure for this bone loss around functional dental implants. Based on their proposed criteria, an average bone loss of $1.2 \mathrm{~mm}$ during the first year of function and $0.2 \mathrm{~mm}$ of bone loss in subsequent years has been deemed agreeable ${ }^{[1,2]}$.

Despite all emerging research, there has been very little consensus on the exact etiology of the observed progressive bone loss around functional dental implants ${ }^{[3]}$. Several hypotheses have been put forward to explain this phenomenon; surgical trauma, periosteal flap elevation, occlusal overload, peri-implantitis, micro-gap, establishment of biological width and crestal module are amongst the more researched proposed etiologies ${ }^{[3]}$.

Crestal module is a factor that has been named as an etiological factor for early crestal bone loss. It is defined as the compartment that endures the highest stresses endured by the crestal region of dental implants ${ }^{[4]}$. In a study by Goswami $\mathrm{MM}^{[5]}$, rough and smooth crestal modules were employed in 40 implants. After 6 months of submerged healing, implants were exposed and loaded prosthetically.
Twelve ${ }^{[12]}$ months subsequent to loading the animals were sacrificed and bone levels measured histologically. It was demonstrated that a statistically significant marginal bone loss was observed around smooth collar implants compared to microthreaded (rough) collar implants. Due to clinically insignificant differences between the figures ${ }^{[5]}$, the true effects of crestal module on marginal bone levels around dental implants are considered insufficient and further studies to clarify the role of this variable are still required.

The aim of the current study was to compare the early radiographic bone level changes around delayed single implants in the posterior maxilla with a beveled $1.5 \mathrm{~mm}$ smooth collar and a beveled $0.3 \mathrm{~mm}$ smooth collar.

\section{PATIENTS AND METHODS}

\section{Patients:}

Patients referred to the department of Oral and Maxillofacial Surgery (Faculty of Dentistry, AinShams University, Cairo, Egypt) for single-implant treatment in the posterior maxillary region were considered for inclusion if they fulfilled the following criteria:

- At least 20 years of age (6).

- In general good health condition, able to undergo surgical treatment (ASA1/ASA2). 
- Adequate oral hygiene, i.e. modified plaque index score and modified sulcus bleeding index score $\leq 1^{[7]}$.

- Absence of clinically active periodontal disease in the sextant receiving the dental implant.

- Single tooth replacements for posterior sites in maxilla. The single edentulous spans can be in any of the locations from first premolar to second molar site and adjacent natural teeth should be present.

- Healed edentulous spans for at least 6 months after tooth extraction having a minimum of $7.5 \mathrm{~mm}$ bucco-palatal bone width at time of implant placement.

- An apico-coronal bone height of at least $7 \mathrm{~mm}$.

- An interarch distance of at least $6 \mathrm{~mm}$ to allow for screw retained restorations.

- And opposed by natural dentition or natural dentition with fixed restorations.

\section{Exclusion criteria were:}

- Presence of acute infection at the implant site.

- $\quad$ Smoking $>10$ cigarettes/day ${ }^{[8]}$.

- Uncontrolled diabetes $(\mathrm{HbA} 1 \mathrm{C}>7 \%)^{[9]}$.

- Medically compromised patients (metabolic diseases, immunodeficiency or treatment with immunosuppressive therapy, previous or current use of oral or intravenous bisphosphonates, etc...).

- A history of irradiation of the head or neck region or chemotherapy within the past 12 months.

- Current bruxism or clenching habits.

\section{Study design:}

This prospective, randomized clinical study was reviewed and approved by the Research Ethical Committee of the Faculty of Dentistry, Ain Shams University. A written informed consent was obtained from all eligible patients before enrolment.

A total of 13 patients in need of dental implant treatment in the posterior maxilla were included in this study where they received a total of 14 dental implants. The patients were randomly allocated to one of two groups, so that each group included a total of 7 implants. Randomization was simply achieved by tossing a coin before the surgery. Group I patients received implants with a smooth bevel $1.5 \mathrm{~mm}$ collar height, while Group II patients received implants with a smooth bevel $0.3 \mathrm{~mm}$ collar height.

\section{Implant design:}

Alumina-particle sandblasted and hydrochloric acid etched rough- surface (Dentium Co. Ltd, Suwon, Korea) tapered implants were used with two different smooth beveled collar heights: $1.5 \mathrm{~mm}$ (Group I) and $0.3 \mathrm{~mm}$ (Group II). Implant diameters were fixed for both groups $4.5 \mathrm{~mm}$ at the implant body and $4.4 \mathrm{~mm}$ diameter at platform level with lengths of 7 and $10 \mathrm{~mm}$.

\section{Preoperative preparation:}

All patients included in the study received clinical and radiographic assessment. Intraoral clinical examination of the prospective implant sites was performed to assess the available restorative space mesio-distally and occlusogingivally, the amount and status of the keratinized mucosa, and the nature of the opposing occlusion. Radiographic Cone-beam computed tomography was also performed to assess the available bone height and width.

One day before implant surgery, patients began taking prophylactic antibiotics (Amoxicillin/Clavulanic acid $875 \mathrm{mg} / 125 \mathrm{mg}$, twice daily for 7 days or clindamycin $300 \mathrm{mg}$, four times daily for 7 days in case of penicillin allergy) and using a $0.12 \%$ Chlorhexidine mouthwash (two times daily for 7 days) for oral disinfection.

\section{Surgical procedure:}

Antisepsis was performed intraorally with $0.12 \%$ chlorhexidine rinse for 1 minute (Hexitol Mouthwash, ADCO, Egypt). Field block anesthetic technique using $4.0 \%$ Articaine solution with 1:100,000 epinephrine (Artinibsa $4 \%$, Inibsa, Spain). Following local anaesthesia, a slightly palatal crest-incision was made with no vertical releasing incisions. Mucoperiosteal flaps were elevated, the alveolar bony ridge was exposed and the osteotomy was performed under abundant irrigation with sterile saline solution. Implants were placed according to the manufacturer's drilling protocol following a two-stage surgical protocol.

All implants placed in Group I had a diameter of $4.5 \mathrm{~mm}$ at the implant body and $4.4 \mathrm{~mm}$ diameter at platform level with fixed lengths of $7 \mathrm{~mm}$. The smooth collar height is 1.5 $\mathrm{mm}$ and the implant body length is $5.5 \mathrm{~mm}$. Those implants were placed such that their smooth rough interface was positioned $1 \mathrm{~mm}$ subcrestally. While those implants placed in Group II had a diameter of $4.5 \mathrm{~mm}$ at the implant body and $4.4 \mathrm{~mm}$ diameter at platform level with fixed lengths of $10 \mathrm{~mm}$. The smooth collar height is $0.3 \mathrm{~mm}$ and the implant body length is $9.7 \mathrm{~mm}$. Those implants were placed such that their smooth rough interface was also positioned $1 \mathrm{~mm}$ subcrestally. Only implants in Group II were placed with bone added osteotome sinus floor elevation if necessary in order to accommodate their lengths at the prospective implant sites. The bone grafting material used was an anorganic bovine bone mineral (BioOss, Geistlich Pharma North America, Geistlich Biomaterials).

Primary stability was measured for all implants by means of resonance frequency analysis (RFA) (Osstell ISQ Integration Diagnostics). Flaps were then repositioned, and interrupted sutures (Vicryl 4 / 0, Assucryl Sutures, Assiut) were done. 


\section{Postoperative care:}

The antibiotic was continued for 6 more days postoperatively, a nonsteroidal anti-inflammatory drug (Ibuprofen $600 \mathrm{mg}$ three times daily for 3 days). For Group II patients, a decongestant (Oxymetazoline nasal drops $0.25 \%$ three times daily for 3 days) was additionally prescribed incase a bone added osteotome sinus floor elevation was performed. Sutures were removed after 10 days. One to two weeks later, patients were recalled for a follow-up visit for inspection of the surgical wound, clinical assessment of the healing process and to exclude any signs of infection.

During the healing phase, patients did not wear a removable partial denture so that it does not interfere with the wound and implant healing. After 4 months, implants were uncovered and a healing abutment (Dentium Co.) was installed.

\section{Prosthetic phase:}

Two weeks after the second-stage surgery, indirect closed-tray implant level impressions were taken and screw retained single layered zirconia final restorations were delivered.

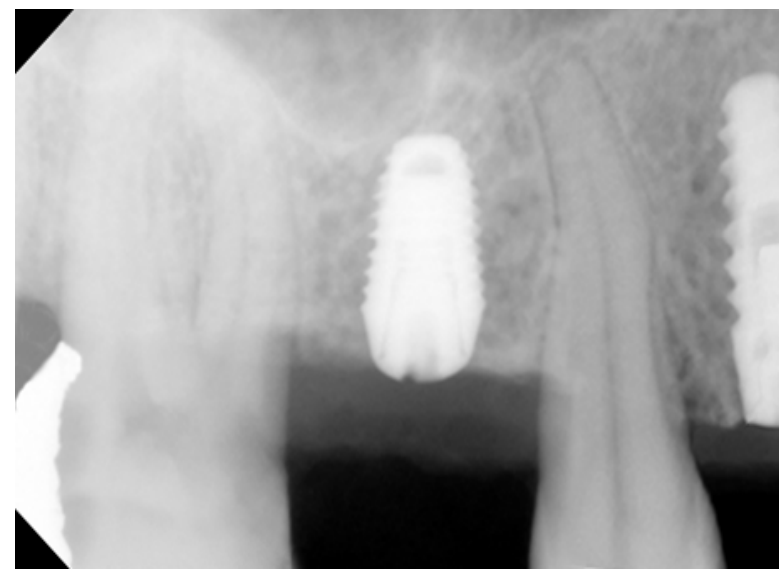

Figure 1: Immediate postoperative (T0) periapical radiograph of Group I Implants using Paralleling Technique.

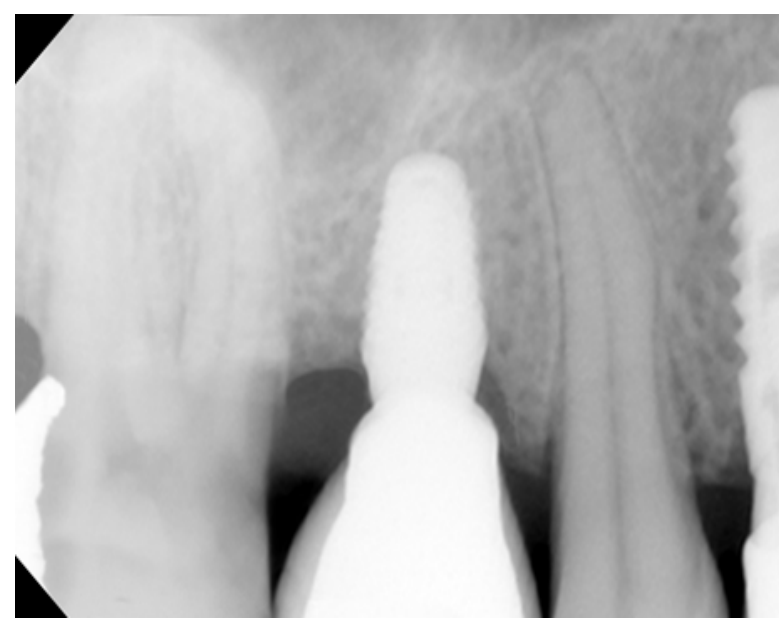

Figure 2: A 6-month follow-up (T10) periapical of Group I Implants using Paralleling Technique.

\section{Follow up phase:}

Six months post loading; all patients were recalled for assessment and implants were examined radiographically.

\section{Outcome assessment:}

The main objective of this study was to assess the crestal bone level changes proximal to the implants 10 months after implant placement (6 months of functional loading) measured on radiographs. The crestal bone level measurements were done using the digital parallel technique with a film holder for standardization immediately after implant placement (T0) (Figures 1 and 3), at stage two surgical procedure 4 months after implant placement (T4), and after 6 months of functional loading (T10) (Figures 2 and 4). Radiographic analysis of the radiographs was performed using specifically designed software (Image ${ }^{[10]}$. First, the radiographs were calibrated according to the known actual implant length. Crestal bone level changes around implants were measured and evaluated. The vertical bone loss was measured directly using the software and then calculated to obtain the actual vertical loss.

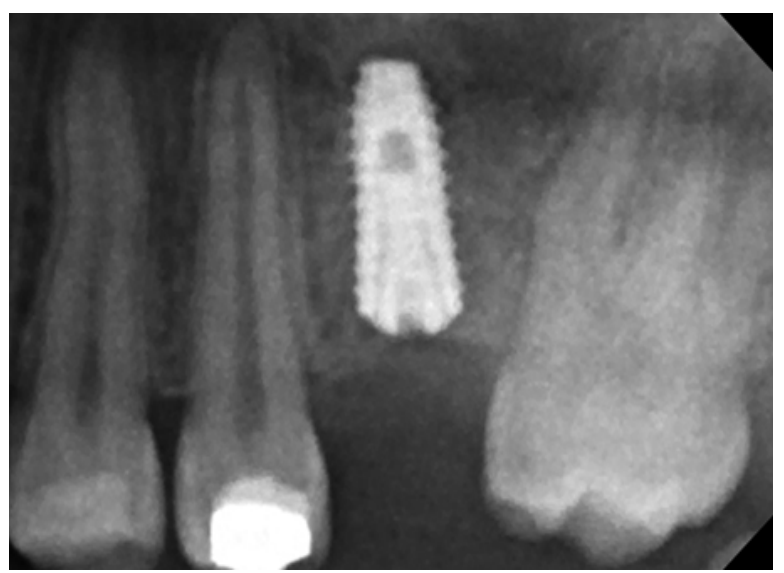

Figure 3: Immediate postoperative (T0) periapical radiograph of Group II Implants using Paralleling Technique.

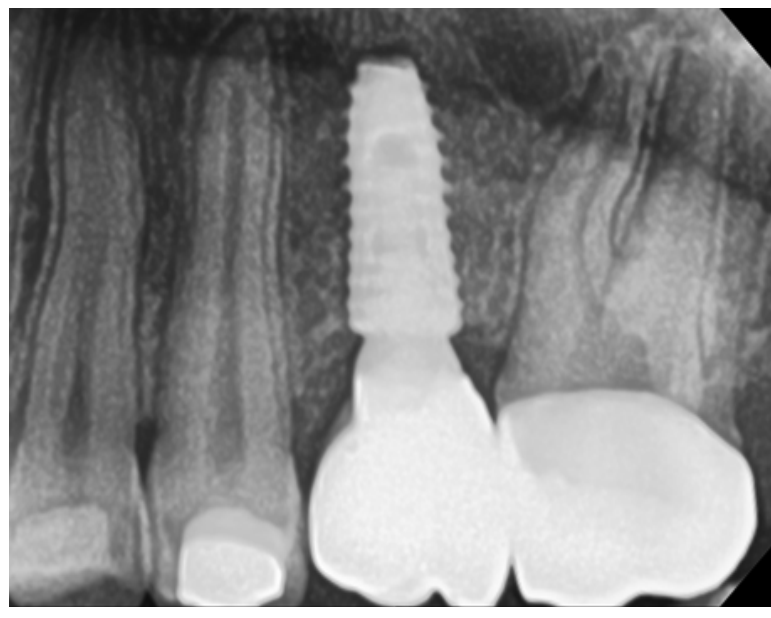

Figure 4: A 6-month follow-up (T10) periapical of Group II Implants using Paralleling Technique. 


\section{RESULTS}

\section{Patients:}

A total of 13 patients receiving 14 implants were allocated to the groups of this study (Table 1). The most frequent location was the area of maxillary $1^{\text {st }}$ molar (8 implants), followed by maxillary $2^{\text {nd }}$ molar ( 5 implants), and maxillary $2^{\text {nd }}$ premolar (1 implant). Six were males $(46 \%)$ and seven were females (54\%). There was no significant difference in age and gender distribution between both groups. All implants could be inserted with good primary stability, with a mean ISQ value of 70 for Group I and a mean ISQ value of 77 for Group II. No pre-implant augmentation procedures were done in both groups. All patients attended the follow-up visit 6 months post loading.

\section{Changes in bone levels:}

Independent Student t-test was conducted to compare marginal bone level and marginal bone loss between treatment groups at different follow-up periods.

\section{A. Comparison of marginal bone level between both groups at each follow-up period:}

Independent Student t-test (Table 2 and Figure 5) showed that there were no statistically significant differences in mesial and distal marginal bone level mean values between both groups within each follow-up period.

Table 1: Mean, Standard Deviation (SD), Frequencies (n) Percentages (\%) and P-value for demographic data

\begin{tabular}{|c|c|c|c|c|c|}
\hline Dem & hic data & Total $(\mathrm{N}=13)$ & Group I $(\mathrm{N}=7)$ & Group II $(\mathrm{N}=6)$ & P-value \\
\hline & ears) & $41.14 \pm 6.12$ & $41.57 \pm 3.36$ & $40.71 \pm 8.34$ & $0.564 \mathrm{NS}$ \\
\hline \multirow{2}{*}{ Gender } & Male & $6(46 \%)$ & $3(43 \%)$ & $3(50 \%)$ & \multirow{2}{*}{$0.593 \mathrm{NS}$} \\
\hline & Female & $7(54 \%)$ & $4(57 \%)$ & $3(50 \%)$ & \\
\hline
\end{tabular}

NS: Non-Significant at $P>0.05$.

Table 2: Mean \pm Standard Deviation (SD) and P-value for the comparison of marginal bone level (mm) between both groups at each followup period

\begin{tabular}{|c|c|c|c|c|c|c|}
\hline & \multicolumn{2}{|l|}{ Mesial } & \multirow{2}{*}{$\mathrm{P}$-value } & \multicolumn{2}{|l|}{ Distal } & \multirow{2}{*}{ P-value } \\
\hline & Group 1 & Group 2 & & Group 1 & Group 2 & \\
\hline At Implant Insertion & $1.45 \pm 0.49$ & $1.20 \pm 0.54$ & $0.429 \mathrm{NS}$ & $0.71 \pm 0.47$ & $0.53 \pm 0.22$ & $0.413 \mathrm{NS}$ \\
\hline Second Stage & $1.12 \pm 0.46$ & $0.93 \pm 0.46$ & $0.509 \mathrm{NS}$ & $0.50 \pm 0.49$ & $0.34 \pm 0.21$ & $0.456 \mathrm{NS}$ \\
\hline 6 Months Of Loading & $0.86 \pm 0.36$ & $0.72 \pm 0.39$ & $0.537 \mathrm{NS}$ & $0.29 \pm 0.53$ & $0.22 \pm 0.22$ & $0.746 \mathrm{NS}$ \\
\hline
\end{tabular}

NS: Non- Significant at $P>0.05$.

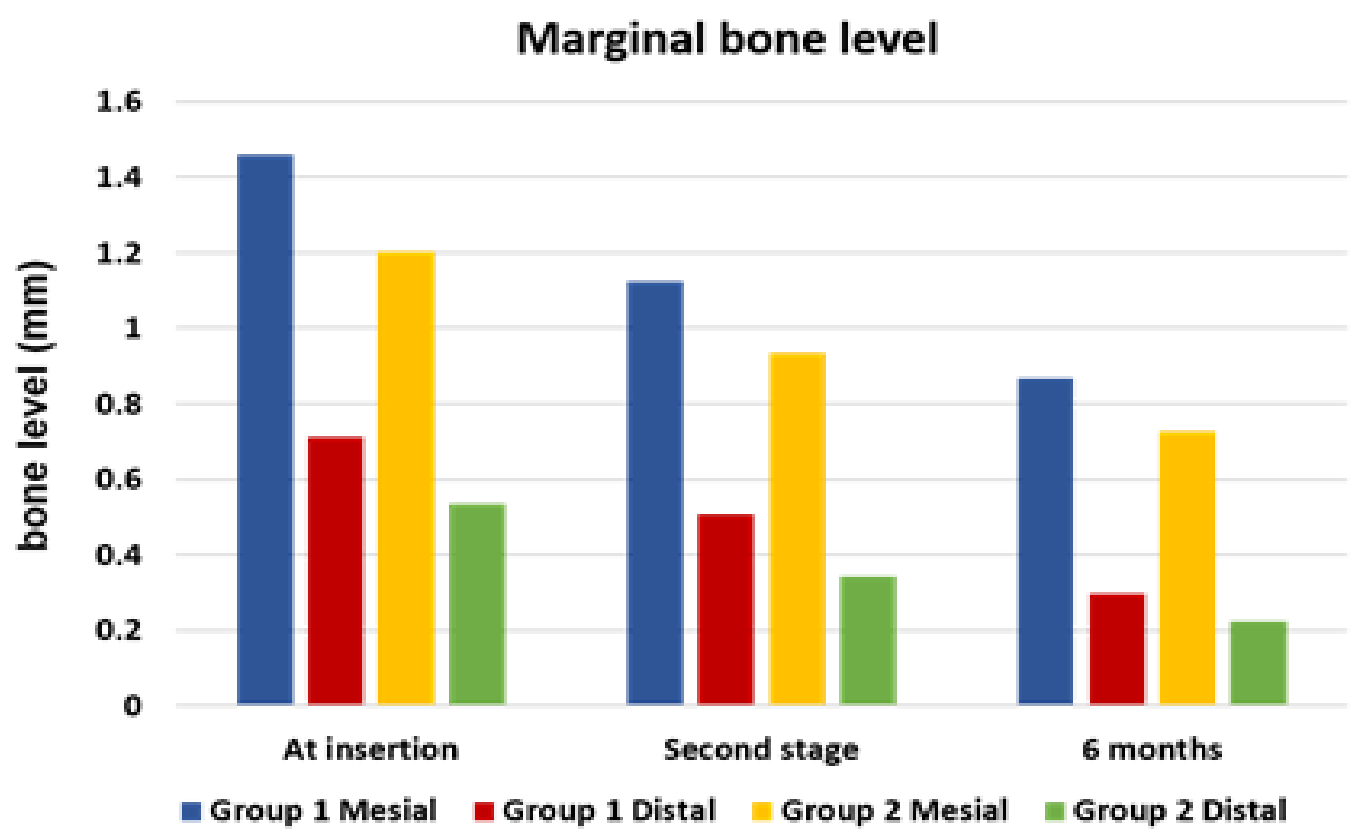

Figure 5: Bar chart for the comparison of marginal bone level $(\mathrm{mm})$ between both groups at each follow-up period. 


\section{B. Comparison of marginal bone loss between both groups at each time interval:}

Independent Student t-test (Table 3 and Figure 6) showed that there were no statistically significant differences in mesial and distal marginal bone loss mean values between both treatment groups within each time interval. are in line with values reported in other studies on single implants placed in the posterior maxilla (11). These results conforms also with Herrero-Climent et al trial revealing that peri-implant crestal bone level were similar for both 0.7 and $1.5 \mathrm{~mm}$ machined collar implant in both maxillary and mandibular posterior regions.(12) Similarly, Joy et al found no statistically significant differences in marginal bone levels (MBL) between 2.8 and $1.8 \mathrm{~mm}$ polished-collar

Table 3: Mean \pm Standard Deviation (SD) and P-value for the comparison of marginal bone loss $(\mathrm{mm})$ between both groups at each time interval

\begin{tabular}{|c|c|c|c|c|c|c|}
\hline & \multicolumn{2}{|l|}{ Mesial } & \multirow{2}{*}{ P-value } & \multicolumn{2}{|l|}{ Distal } & \multirow{2}{*}{ P-value } \\
\hline & Group 1 & Group 2 & & Group 1 & Group 2 & \\
\hline At insertion - Second stage & $0.33 \pm 0.15$ & $0.26 \pm 0.11$ & $0.394 \mathrm{NS}$ & $0.20 \pm 0.09$ & $0.19 \pm 0.03$ & $0.775 \mathrm{NS}$ \\
\hline Second Stage -6 Months follow up & $0.25 \pm 0.13$ & $0.21 \pm 0.09$ & $0.487 \mathrm{NS}$ & $0.21 \pm 0.09$ & $0.12 \pm 0.02$ & $0.54 \mathrm{NS}$ \\
\hline At insertion - 6 Months follow up & $0.59 \pm 0.23$ & $0.47 \pm 0.18$ & $0.385 \mathrm{NS}$ & $0.41 \pm 0.17$ & $0.31 \pm 0.04$ & $0.174 \mathrm{NS}$ \\
\hline
\end{tabular}

NS: Non - Significant at $P>0.05$

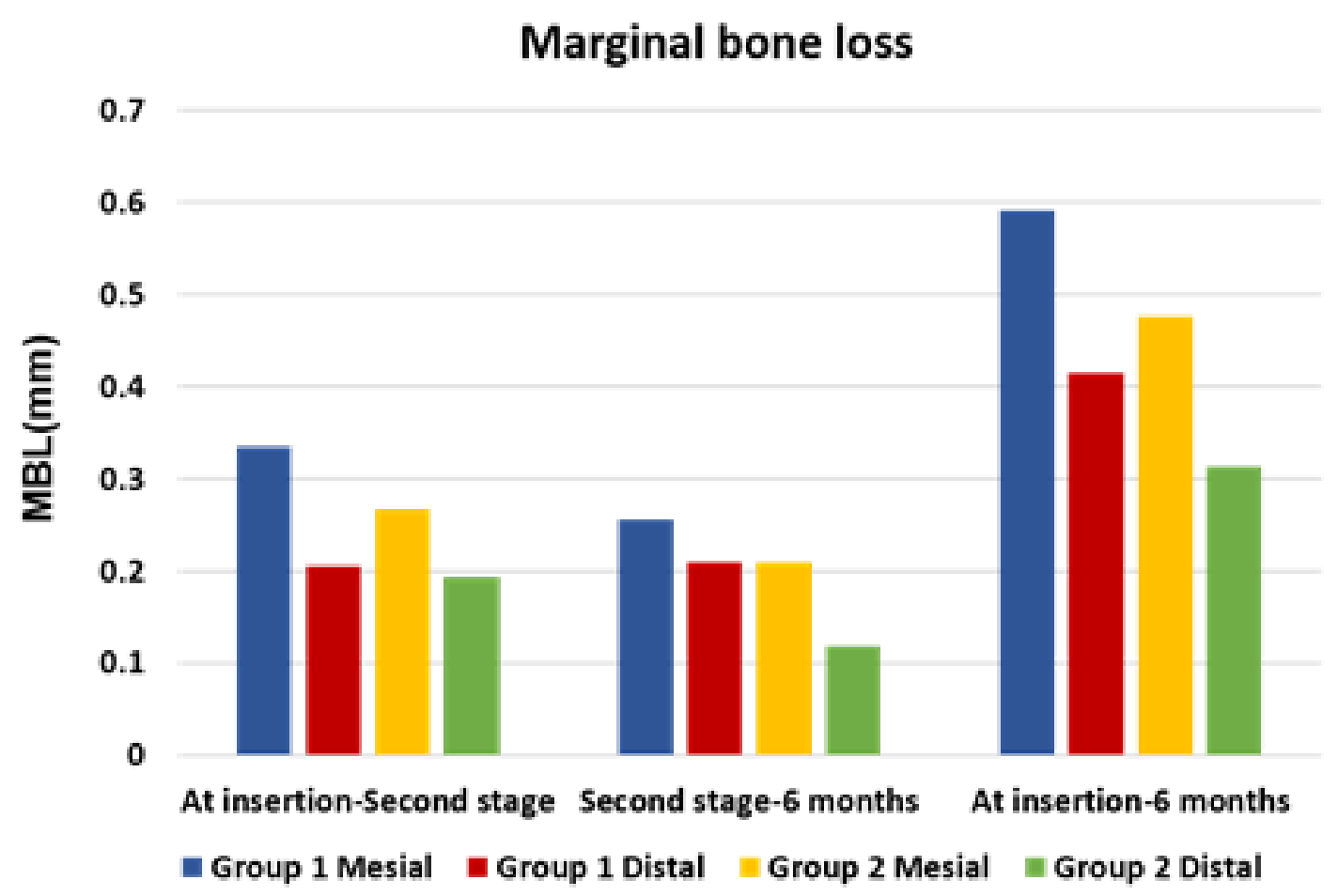

Figure 6: Bar chart for the comparison of marginal bone loss $(\mathrm{mm})$ between both groups at each time interval.

\section{DISCUSSION}

This study compared the effect of two different implant smooth collar heights on preservation of crestal bone for single implants in the posterior maxilla. Implants had a beveled $1.5 \mathrm{~mm}$ smooth collar and a beveled $0.3 \mathrm{~mm}$ smooth collar. The results of our study showed that after 6 months of loading, there was no significant difference in radiographic marginal bone loss between both groups.

Both smooth collar groups revealed favorable treatment outcomes in terms of bone loss and implant survival, which implants placed in the posterior mandibular regions ${ }^{[13]}$.

On the other hand, several other studies have demonstrated significantly more marginal bone loss around implants with a smooth collar ${ }^{[14-18]}$. Because some of these studies mainly focused on other sites than the posterior maxilla. For instance, Nickenig et al. ${ }^{[18]}$ compared smooth and rough implants in the mandibular molar region.

In our study, all implants were placed such that their smooth rough interface was positioned $1 \mathrm{~mm}$ subcrestally. It has been found that the position of the smooth-rough 
interface relative to the bone crest at the time of implant placement is a significant factor for marginal bone loss ${ }^{[14,19,20]}$. However, Hämmerle et al did not find any clinical or radiographic statistically significant difference in MBL with $2.8 \mathrm{~mm}$ polished-collar implants. It was comparing the placement of the smooth-rough interface either at bone crest level or $1 \mathrm{~mm}$ sub-crestal. After 12 months, the distances between the bone crest and implant shoulder were $2.6 \pm 0.8 \mathrm{~mm}$ and $2.5 \pm 0.7 \mathrm{~mm}$ respectively ${ }^{[21]}$. The MBL may rather depend on the abutment-implant interface level than the smooth-collar height $^{[12]}$.

At the end of the current study, we could not prove any scientific evidence to favor the use of specific smooth collar height over another when restoring single teeth in posterior maxilla. Both designs showed comparable acceptable amount of MBL for a successful implant. Despite that, larger number of patients and longer follow-up period are needed to confirm this.

\section{CONFLICT OF INTEREST}

The authors declare no conflict of interest.

\section{REFERENCES}

1. Albrektsson T, Zarb G, Worthington P, Eriksson AR. The long-term efficacy of currently used dental implants: A review and proposed criteria of success. Int $\mathrm{J}$ Oral Maxillofac Implants 1986; 1:11- 25.

2. Smith DE, Zarb GA. Criteria for success of osseointegrated endosseous implants. J Prosthet Dent 1989 Nov;62(5):567 - 72.

3. Bragger U, Hafeli U, Huber B, Hammerle $\mathrm{CH}$, Lang NP. Evaluation of postsurgical crestal bone levels adjacent to non-submerged dental implants. Clin Oral Implants Res. 1998; 9:218 - 224.

4. Aparna I N, Dhanasekar B, Lingeshwar D, Gupta L. Implant crest module: A review of biomechanical considerations. Indian $\mathrm{J}$ Dent Res 2012; 23:257 - 63.

5. Goswami MM. Comparison of crestal bone loss along two implant crest module designs. Med J Armed Forces India 2009 Oct;65(4):319 - 22.

6. Heij DG, Opdebeeck $\mathrm{H}$, van Steenberghe D, Kokich VG, Belser U, Quirynen M. Facial development, continuous tooth eruption and mesial drift as compromising factors for implant placement. International Journal of Oral and Maxillofacial Implants. 2006 Nov/Dec;21(6):867 - 878.
7. Mombelli A, van Oosten MA, Schurch E Jr, Land NP. The microbiota associated with successful or failing osseointegrated titanium implants. Oral MicrobiolImmunol. 1987 Dec;2(4):145 - 51.

8. Schwartz-Arad D, Samet N, Samet N, Mamlider A. Smoking and complications of endosseous dental implants. J Periodontol 2002 Feb; 73:153 - 157.

9. Ormianer Z, Block J, Matalon S. The Effect of moderately controlled type 2 diabetes on dental implant survival and peri-implant bone loss: A long-term retrospective study. International Journal of Oral and Maxillofacial Implants. 2018 Mar;33(2): 389 - 394.

10. Preus, HR, Torgersen GR, Koldsland OC, Hansen BF, Aass AM, Larheim TA, Sandvik L. A new digital tool for radiographic bone level measurements in longitudinal studies. BMC Oral Health 2015; 15: 107.

11. Ajanovic M, Hamzic A, Redzepagic S, KamberCesir A, Kazazic L, Tosum S. Radiographic Evaluation of Crestal Bone Loss Around Dental Implants in Maxilla and Mandible: One Year Prospective Clinical Study. Acta Stomatol Croat 2015 Jun;49(2): 128 - 136.

12. Herrero-Climent M, Ruiz MM, Díaz-Castro CM, Bullón P, Ríos-Santos JV. Influence of two different machined-collar heights on crestal bone loss. International Journal of Oral and Maxillofacial Implants. 2014 Dec 1;29(6). 1374 - 1379.

13. Joly JC, de Lima AF, Da Silva RC. Clinical and radiographic evaluation of soft and hard tissue changes around implants: A pilot study. Journal of periodontology. 2003 Aug 1;74(8):1097 - 103.

14. Hermann J.S., Buser D., Schenk R.K., Schoolfield J.D. and Cochran D.L. Biologic width around oneand two-piece titanium implants. Clinical Oral Implants Research 2001; 12: 559 - 571.

15. Schwarz F., Herten M., Bieling K. and Becker J. Crestal bone changes at nonsubmerged implants (Camlog) with different machined collar lengths: a histomorphometric pilot study in dogs. The International Journal of Oral and Maxillofacial Implants 2008; 23: $335-342$.

16. Bratu E.A., Tandlich M. and Shapira L. A rough surface implant neck with microthreads reduces the amount of marginal bone loss: a prospective clinical study. Clinical Oral Implants Research 2009; 20: $827-832$. 
17. Stein A.E., McGlmphy E.A., Johnston W.M. and Larsen P.E. Effects of implant design and surface roughness on crestal bone and soft tissue levels in the esthetic zone. The International Journal of Oral and Maxillofacial Implants 2009; 24: 910 - 919.

18. Nickenig H.J., Wichmann M., Schlegel K.A., Nkenke E. and Eitner S. Radiographic evaluation of marginal bone levels adjacent to parallel-screw cylinder machined-neck implants and roughsurfaced micro-threaded implants using digitized panoramic radiographs. Clinical Oral Implants Research 2009; 20: 550 - 554.

19. Broggini N., McManus L.M., Hermann J.S., Medina R., Schenk R.K., Buser D. and Cochran
D.L. Peri-implant inflammation defined by the implant- abutment interface. Journal of Dental Research 2006; 85: 473 - 478.

20. Jung R.E., Jones A.A., Higginbottom F.L., Wilson T.G., Schoolfield J., Buser D., Hammerle C.H. and Cochran D.L. The influence of nonmatching implant and abutment diameters on radiographic crestal bone levels in dogs. Journal of Periodontology 2008; 79: $260-270$.

21. Hämmerle $\mathrm{CH}$, Brägger $\mathrm{U}$, Bürgin $\mathrm{W}$, Lang NP. The effect of subcrestal placement of the polished surface of ITI implants on marginal soft and hard tissues. Clinical oral implants research. 1996 Jun;7(2):111 - 119. 